\title{
Acardiac Acephalus with Single Umbilical Artery in Acardiac Twin
}

\author{
Lakshmidevi Muralidhar, Sampath Kumar Govindraj, Shreedhar Venkatesh, Rajini Thimmaiah
}

\begin{abstract}
Twin reversed arterial perfusion (TRAP) sequence (acardiac twin) is one of the rare complications of multifetal gestation which is unique to monochorionic placentation. It affects about $1 \%$ of multifetal gestation and prevalence is one in 35,000 pregnancies. We are presenting a case of acardiac acephalus with ventricular hypertrophy and polyhydramnios of pump twin. Autopsy of acardiac twin was done and various anomalies associated with it were described. Acardiac twin showed anomalies consistent with VACTERL anomalies and single umbilical artery. This case is reported because of the rarity of presentation and to stress the importance of early diagnosis for the proper management of the case. This is taken as an opportunity to describe various modalities of treatment of acardiac twin.
\end{abstract}

Keywords: Acardiac acephalus, Monochorionic placentation, TRAP sequence, Multifetal gestation and anomalies.

How to cite this article: Muralidhar L, Govindraj SK, Venkatesh S, Thimmaiah R. Acardiac Acephalus with Single Umbilical Artery in Acardiac Twin. Int J Infertility F etal Med 2013; 4(3):93-95.

\section{Source of support $\mathrm{Nil}$}

\section{Conflict of interest None}

\section{INTRODUCTION}

Twin reversed arterial perfusion (TRAP) sequence (acardiac twin) is one of the rare complications of multifetal gestation which is unique to monochorionic placentation. It affects about $1 \%$ of multifetal gestation and prevalence is one in 35,000 pregnancies. ${ }^{1}$ Though it was first described in 1533, the number of reported cases is very few. In TRAP sequence, there is either arterial to arterial or veno-venous anatomises between the pump twin and the recipient twin. ${ }^{2}$ we are presenting a case of acardiac acephalus with ventricular hypertrophy and polyhydramnios of pump twin. A utopsy of acardiac twin was done, and various anomalies associated with it were described. A cardiac twin showed anomal ies consistent with VA CTERL anomalies and single umbilical artery. This case is reported because of the rarity of presentation and to stress the importance of early diagnosis for the proper management of the case.

\section{CASE REPORT}

A 28-year-old primigravida with 24 weeks of period of gestation was referred from periphery in latent labor with ultrasonography showing monochorionic monoamniotic twin gestation, with first twin of around 24 weeks without any anomalies and massive hydramnios and 2nd twin acardiac acephalus and massive hydramnios.

On history, there were no significant findings. On examination, abdomen was over distended corresponding to 36 weeks of gestation, tense, fetal parts couldn't be made out distinctly and fetal heart rate was not localized. On pervaginal examination, cervix was $75 \%$ effaced, $4 \mathrm{~cm}$ dilated. Bag of membranes bulging. Repeat ultrasonography and Doppler was done which showed confirmed the findings of old scan with ventricular hypertrophy of pump twin.

Patient delivered an alive female baby of weight $450 \mathrm{gm}$ and acardiac acephalus of around $200 \mathrm{gm}$ delivered with monochorionic placenta arterioarterial anastomosis (Fig. 1). Normal twin shifted to neonatal ICU, and acardiac twin and placenta sent for autopsy in academic interest after taking the consent from mother and her relatives. Normal twin on gross examination was normal and no congenital anomalies. A cardiac twin showed absence of the structures in the upper half of the body, i.e. cranium, thoracic structures that is lungs and heart and upper limb. Prior to sending the specimen for autopsy, X-ray was taken which showed normal bone development in the lower half of the body and distal bone defects.

A cardiac twin was subjected to complete autopsy dissection. The following are the anomalies reported with

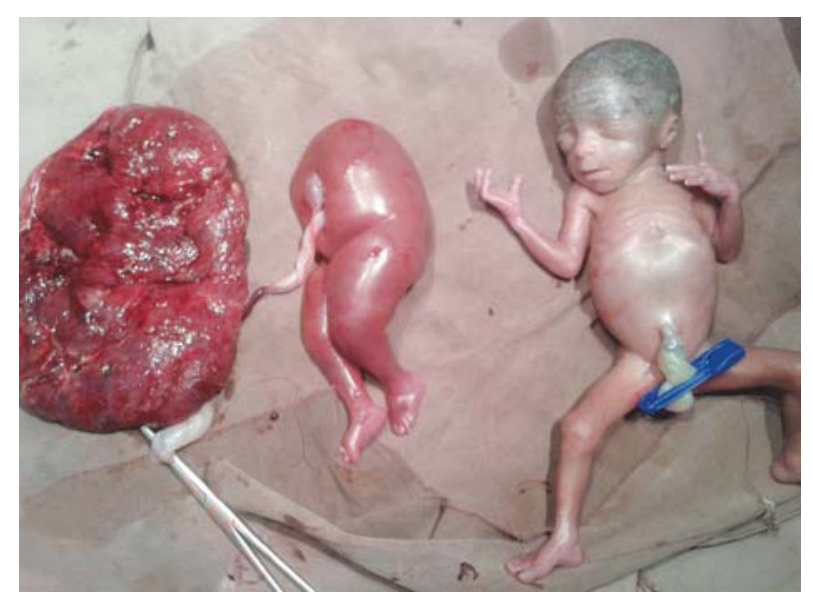

Fig. 1: The placenta, acardiac twin and normal fetus 
it, i.e. single umbilical artery, limb anomalies in the region of toes, imperforate anus, improper development of external genitalia, equinovarus of the lower extremities, only small intestinal structures were developed, large intestine was absent, spleen and stomach were absent. Diaphragm was absent. Liver was developed. Internal genital organs were not developed. Small intestine which was present has blind ends on both the sides and was present within the umbilical cord (Fig. 2).

On complete study of placenta, no communication was found within the placenta but the communication was directly near the insertion of umbilical cord of pumping twin between two arteries. Placenta was velamentous and showed marginal insertion of both the cord structures. Placenta was monochorionic and, on complete dissection of the placenta, there was no vascul ar communication between the umbilical cord of the recipient twin and the placenta (Fig. 3).

\section{DISCUSSION}

There are two theories put forward for the development of acardiac twin: one is genetic defect in the fetus sufficient to cause failure of cardiac development in the fetus. Proposed hypothesis for the cardiac anomaly is post-zygotic nondysjunction. Other theory proposed is development of anastomosis in between the two vessels of the umbilical cord. A rterio arterial anastomosis early in the first trimester leading to vascular disruption of one twin and devel opment of TRA P sequence. O ur case strongly supports this theory as the placental dissection showed communication between umbilical arteries of acardiac twin with normal twin at insertion. ${ }^{3,4}$

A cardiac twin is associated with single umbilical artery in $66 \%$ and chromosomal abnormalities in $33 \%$ of the cases. ${ }^{5}$ M ortality for pump is about 50 to $75 \%$. Early diagnosis is very essential for the proper management of pump twin.

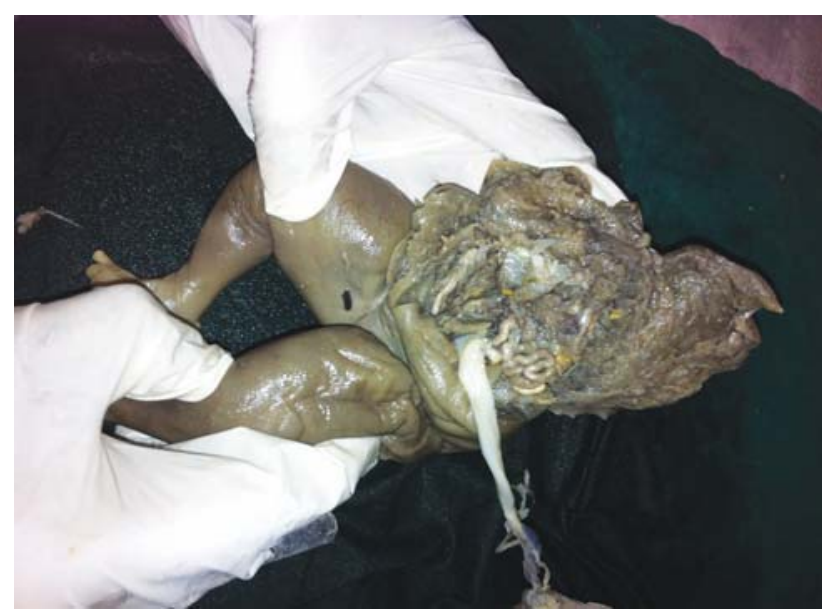

Fig. 2: The autopsy specimen of acardiac fetus

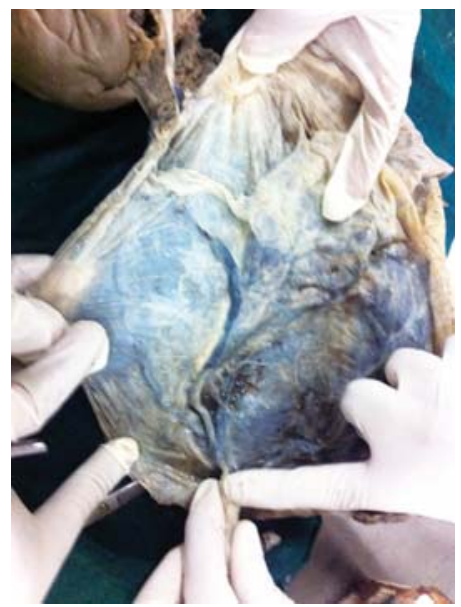

Fig. 3: The placenta with arterio-arterial anastomosis

M edical treatment has been tried with indomethacin and digoxin with limited success. ${ }^{6}$ Conservative management is advised unless one of the following poor prognostic indicators is present. Unnecessary intervention will only increase the risk of mortality of the pump twin. Poor prognostic factors are development of: (1) polyhydramnios, (2) ultrasound indicators of cardiac insufficiency, like tricuspid regurgitation, pulsatile umbilical vein and abnormal pulsatile waveform in pulsatile twin, (3) large acardiac twins and rapid growth of acardiac twin. ${ }^{7}$

$V$ arious modalities have been described in the management of acardiac twin, earlier methods, like fetoscopic ligation of cord of acardiac twin and fetoscopic laser coagulation. The disadvantages of this methods are they are more invasive, frequently may require an additional port leading septotomy and iatrogenic pseudo amnionicity leading to increased chances of cord entanglement, the main disadvantage is technical difficulty in visualising the umbilical cord of acardiac twin. Perinatal mortality associated with this technique is $30 \%$ and preterm delivery is $70 \%$. Newer treatment modalities include ultrasound-guided intrafetal approach. It includes intrafetal vascular ablation. The methods include monopolar coagulation, laser coagulation and radiofrequency ablation. Intrafetal approach simple, safe and effective. They are less invasive and have high rate of clinical success. Doppler clearly identifies the main intrafetal branch making it easier to access. Therefore, it is the preferred modality of treatment. ${ }^{7}$

Our case is presented because of the rarity of the case and to stress the importance of early diagnosis for the proper management of the pump twin.

\section{REFERENCES}

1. Gezer C, Tatli O, Soylu F, Erkan L, Ince E. Successful intrauterine treatment with radiofrequency ablation in twin reversed arterial perfusion (TRAP) sequence: a case report and review of literature. A ntol J Obstet Gynecol 2010;2:3. 
2. A thwal S, M illard K, L akhoo K. Twin reversed arterial perfusion (TRAP) sequence in association with VACTERL association. J ournal of M edical Case Reports 2010;4:411-413.

3. Chaliha $C$, Schwarzler P, Booker M, Battash M A, Ville $Y$. Case report trisomy 2 in an acardiac twin in a triplet in vitro fertilization pregnancy. Human Reproduction 1999;14(5): 1378-1380.

4. Schwärzler P, VilleY, M oscosco G, Tennstedt C, B ollmann R, Chaoui R. Diagnosis of twin reversed arterial perfusion sequence in the first trimester by transvaginal color doppler ultrasound. Ultrasound Obstet Gynecol 1999;13:143-146.

5. Dar Owvass H, B hau Shalinder S, Bhau Kulwant S, Parihar Ravi K. A cardiac parabiotic triplet. JK Science 2011 J uly-Sep; 13(3):1663-1666.

6. J olly M, Taylor M, Rose G, Govender L. Fisk interstitial laser: a new surgical technique for twin reversed arterial perfusion sequence in early pregnancy. Br J Obstet Gynaecol 2001;108: 1098-1102.

7. Wiley J. Opinion acardiac twin: too many invasive treatment options- the problem and not the solution. Ultrasound Obstet Gynecol 2004;24:387-389.

\section{ABOUT THE AUTHORS}

\section{Lakshmidevi Muralidhar (Corresponding Author)}

A ssistant Professor, D epartment of O bstetrics and Gynecology, V ydehi Institute of M edical Sciences and Research Centre, B engal uru, Karnataka India, Phone: 9886602627, e-mail: dr_lakshmi_m1982@yahoo.co.in

\section{Sampath Kumar Govindraj}

Professor, Department of O bstetrics and Gynecology, $V$ ydehi Institute of M edical Sciences and R esearch Centre, B engaluru, K arnataka, India

\section{Shreedhar Venkatesh}

Professor and Head, Department of O bstetrics and Gynecology, $V$ ydehi Institute of Medical Sciences and Research Centre, Bengaluru Karnataka, India

\section{Rajini Thimmaiah}

Professor, Department of A natomy, Vydehi Institute of Medical Sciences and Research Centre, B engaluru, K arnataka, India 